\title{
Response of Amaranthus retroflexus L. seeds to gibberellic acid, ethylene and abscisic acid depending on duration of stratification and burial
}

\author{
Jan Kępczyński · Paweł Sznigir
}

Received: 6 June 2012/ Accepted: 29 November 2012/Published online: 23 December 2012

(C) The Author(s) 2012. This article is published with open access at Springerlink.com

\begin{abstract}
Freshly harvested, dormant seeds of Amaranthus retroflexus were unable to germinate at 25 and $35^{\circ} \mathrm{C}$. To release their dormancy at the above temperatures, the seeds were stratified at a constant temperature $\left(4^{\circ} \mathrm{C}\right)$ under laboratory conditions or at fluctuating temperatures in soil or by outdoor burial in soil. Fully dormant, or seeds stratified or buried (2006/2007 and 2007/2008) for various periods were treated with exogenous gibberellic acid $\left(\mathrm{GA}_{3}\right)$, ethephon and abscisic acid (ABA). Likewise, the effects of these regulators, applied during stratification, on seed germination were determined. The results indicate that $A$. retroflexus seed dormancy can be released either by stratification or by autumnwinter burial. The effect of $\mathrm{GA}_{3}$ and ethylene, liberated from ethephon, applied after various periods of stratification or during stratification, depends on dormancy level. $\mathrm{GA}_{3}$ did not affect or only slightly stimulated the germination of nonstratified, fully dormant seeds at 25 and $35^{\circ} \mathrm{C}$ respectively. Ethylene increased germination at both temperatures. Seed response to $\mathrm{GA}_{3}$ and ethylene at $25^{\circ} \mathrm{C}$ was increased when dormancy was partially removed by stratification at constant or fluctuating temperatures or autumn-winter burial. The response to $\mathrm{GA}_{3}$ and ethylene increased with increasing time of stratification. The presence of $\mathrm{GA}_{3}$ and ethephon during stratification may stimulate germination at $35^{\circ} \mathrm{C}$. Thus, both $\mathrm{GA}_{3}$ and ethylene can partially substitute the requirement for stratification or autumn-winter burial. Both hormones may also stimulate germination of secondary dormant seeds, exhumed in September. The response to ABA decreased in parallel with an increasing time of stratification and burial up
\end{abstract}

J. Kępczyński $(\square) \cdot$ P. Sznigir

Department of Plant Physiology and Genetic Engineering,

Faculty of Biology, University of Szczecin, Waska 13,

71-415 Szczecin, Poland

e-mail: jankepcz@wp.pl to May 2007 or March 2008. Endogenous $\mathrm{GA}_{n}$, ethylene and ABA may be involved in the control of dormancy state and germination of A. retroflexus. It is possible that releasing dormancy by stratification or partial burial is associated with changes in $\mathrm{ABA} / \mathrm{GA}$ and ethylene balance and/or sensitivity to these hormones.

Keywords Amaranthus retroflexus · Burial . Germination · Plant hormones · Primary dormancy . Stratification

\section{Introduction}

Seeds of numerous species are not able to germinate after harvest at conditions favorable for the germination process. These seeds are considered as primarily dormant. Such dormancy is induced during seed development and maturation on plants. Seed dormancy is common in wild plants; it may ensure the ability of species to survive natural catastrophes, and decrease competition between individuals of the same species (Finkelstein et al. 2008). Furthermore, it allows seeds of numerous weeds to persist in soil for many years. Under natural conditions, dormant seeds are exposed to fluctuating environmental factors e.g. light, temperature, moisture and the presence of gases which lead to cyclical changes in the dormancy state (Finkelstein et al. 2008). Seed dormancy can be released during burial, cold stratification and dry after-ripening, or by chemicals (Bewley and Black 1994). Dormancy release may involve changes in concentrations of abscisic acid (ABA), gibberellins ( $\left(\mathrm{GA}_{\mathrm{s}}\right)$ and ethylene and/ or a change in sensitivity to these hormones (Hilhorst 2007; Kępczyński and Kępczyńska 1997; Matilla 2000). Application of exogenous $\mathrm{GA}_{3}$ and ethylene can partially or completely remove dormancy in seeds of many plant species. 
Amaranthus retroflexus is an important weed, which infests soil in many parts of the world (Holm et al. 1997), including Poland. As has been shown, buried seeds of A. retroflexus can remain viable for at least 6-10 years (Costea et al. 2004). Dormancy levels of these seeds have been found to vary due to, among other factors, temperature during maturation, fertilization of soil and competition between cultivated plants (Costea et al. 2004). Dormant A. retroflexus seeds could germinate fully in darkness at $35-40{ }^{\circ} \mathrm{C}$ (Kępczyński et al. 1996) or only partially at $35{ }^{\circ} \mathrm{C}$ (Schonbeck and Egley 1981; Kępczyński et al. 2003b). Earlier studies have shown a role for plant hormones in regulating the dormancy state in A. retroflexus seeds. Ethylene, ethephon, an ethylene releasing compound, and 1-aminocyclopropane-1-carboxylic acid (ACC), a precursor of ethylene biosynthesis induced germination of primarily dormant A. retroflexus seeds (Schonbeck and Egley 1981; Kępczyński et al. 1996, 2003b). Likewise, gibberellic acid could remove dormancy in these seeds (Kępczyński et al. 2003 b). It was also shown that dormancy release by $\mathrm{GA}_{3}$ involved ethylene biosynthesis and action (Kępczyński et al. $2003 \mathrm{~b}$ ). However, there is no data comparing the effects of stratification and burial on releasing dormancy of $A$. retroflexus seeds. Similarly, no research has been conducted on the response of these seeds, originating from the same harvest, stratified or buried for various periods, to gibberellin, ethylene and abscisic acids.

The aim of the present study was to determine the effects of $\mathrm{GA}_{3}$, ethephon or ABA (1) applied after various periods of stratification, during stratification at constant temperature $\left(4^{\circ} \mathrm{C}\right)$ or after stratification at fluctuating temperature and (2) applied after various periods of burial in soil at seasonal fluctuating temperature on $A$. retroflexus seed germination at 25 and $35^{\circ} \mathrm{C}$ in darkness.

\section{Materials and methods}

Plant material

Amaranthus retroflexus L. seeds were collected from wild populations in September 2006, near Lubniewice in Poland. The inflorescences were stored in open air then shaken gently to remove seeds. 10 days after collection, clean seeds were stored at $-20{ }^{\circ} \mathrm{C}$ until required.

\section{Stratification}

\section{Experiment 1}

Seeds $(0.9 \mathrm{~g})$ were placed in $12 \mathrm{~cm}$ diameter Petri dishes lined with three layers of filter paper moistened with $12 \mathrm{ml}$ distilled water and sealed with parafilm. Petri dishes were placed in darkness at $4{ }^{\circ} \mathrm{C}$ for 20 weeks. Every 2 weeks the seeds were removed and the effects of $\mathrm{GA}_{3}\left(10^{-4}\right.$, $\left.3 \times 10^{-4}, 10^{-3} \mathrm{M}\right)$, ethephon $\left(3 \times 10^{-6}, 10^{-5}, 10^{-4} \mathrm{M}\right)$ and $\mathrm{ABA}\left(10^{-6}, 10^{-5}, 10^{-4} \mathrm{M}\right)$ on their germination at 25 and $35^{\circ} \mathrm{C}$ in darkness determined.

\section{Experiment 2}

Seeds were incubated at $4{ }^{\circ} \mathrm{C}$ on 3 layers of filter paper moistened with distilled water or solutions of $\mathrm{GA}_{3}$ $\left(10^{-3} \mathrm{M}\right)$, ethephon $\left(10^{-4} \mathrm{M}\right)$ and $\mathrm{ABA}\left(10^{-4} \mathrm{M}\right)$ in $12 \mathrm{~cm}$ Petri dishes sealed with parafilm. After 4, 8 and 12 weeks of stratification, seed germination in water, at $35^{\circ} \mathrm{C}$, in darkness was determined.

\section{Experiment 3}

Seeds $(0.9 \mathrm{~g})$ were placed in $12 \mathrm{~cm}$ diameter Petri dishes lined with three layers of filter paper moistened with $12 \mathrm{ml}$ distilled water, sealed with parafilm and covered with aluminum foil. Then, on 12 November 2007, the Petri dishes were placed outdoors at of $10 \mathrm{~cm}$ depth below the soil surface. After 4 weeks, the seeds were removed in darkness under green light and the effects of $\mathrm{GA}_{3}\left(10^{-4}\right.$, $\left.10^{-3} \mathrm{M}\right)$, ethephon $\left(10^{-5}, 10^{-4} \mathrm{M}\right)$ and $\mathrm{ABA}\left(10^{-6}, 10^{-5}\right.$, $10^{-4} \mathrm{M}$ ) on germination at 25 and $35^{\circ} \mathrm{C}$ in darkness determined. In 2007 the average temperature at $5 \mathrm{~cm}$ below the surface of soil was 4.0 (November) and $3.3^{\circ} \mathrm{C}$ (December). The lowest temperature in November was 2.7 and in December $-7.6^{\circ} \mathrm{C}$. Readings were taken by Szczecin Department of Institute of Meteorology and Water Management (IMGW-PIB).

\section{Burial}

On 6th November 2006 and 4th November 2007, nylon bags which contained $12 \mathrm{~g}$ of seeds, harvested in 2006, were placed in boxes made of metallic net. They were covered with $10 \mathrm{~cm}$ of soil taken from the field where the population of $A$. retroflexus plants used for seed collection had grown. After various periods of burial, seeds were removed in darkness and incubated in water, $\mathrm{GA}_{3}\left(10^{-3}\right.$ $\mathrm{M})$, ethephon $\left(10^{-4} \mathrm{M}\right)$ and $\mathrm{ABA}\left(10^{-4} \mathrm{M}\right)$ solutions in darkness at 25 or $35^{\circ} \mathrm{C}$.

\section{Germination}

Seeds (3 replications of 50) were incubated in $6 \mathrm{~cm}$ diameter glass Petri dishes on one layer of filter paper moistened with $1.5 \mathrm{ml}$ distilled water or appropriate solutions of $\mathrm{GA}_{3}$, ethephon or ABA. Seeds were incubated in darkness for up to 7 days. Germinated seeds were counted every day. Seeds were regarded as germinated when 
the radicle protruded through the seed coat and was longer than $2 \mathrm{~mm}$. All manipulations were performed under green light.

Results were presented as a percentage of seed germination after seven days of incubation. Furthermore, the rate of germination was presented according to Timson (1965) by calculating the value of $\Sigma_{7}\left(\Sigma_{7}=700\right.$ means that $100 \%$ of seeds germinated on the first day).

\section{Statistical analysis}

The average \pm standard deviation (SD) of three independent determinations from 50 seeds each are presented. Data have been analyzed for significance using one-way or twoway ANOVA (Statistica for Windows ver. 9.0, StatSoft Inc., Tulsa, Oklahoma, USA). Duncan's multiple range test was used for determination of significant differences between germination values $(P \leq 0.05)$.

\section{Results}

Effect of $\mathrm{GA}_{3}$, ethephon and $\mathrm{ABA}$ on seed germination after various periods of stratification

\section{Germination at $25^{\circ} \mathrm{C}$}

Freshly harvested $A$. retroflexus seeds did not germinate at $25{ }^{\circ} \mathrm{C}$ (Fig. 1a). Stratification increased seed germination percentage at $25^{\circ} \mathrm{C}$ as time progressed. 16 and 20 weeks of stratification resulted in ca. $40 \%$ germination. $\mathrm{GA}_{3}$, a well-known dormancy releasing factor, did not affect germination of dormant, non-stratified seeds. $\mathrm{GA}_{3}$, at its lowest concentration, i.e. $10^{-4} \mathrm{M}$, did not affect germination of seeds stratified up to 16 weeks and only slightly increased the percentage of germination after 20 weeks. However, a higher concentration of this stimulator, $3 \times 10^{-4} \mathrm{M}$, improved germination beginning from week 4 until the end of the 20 week stratification period. After 16-20 weeks of stratification ca. $70 \%$ of seeds were able to germinate due to the effect of $\mathrm{GA}_{3}$ applied at the above concentration. An application of $\mathrm{GA}_{3}$ at the highest concentration, $10^{-3} \mathrm{M}$, caused ca. $90 \%$ of seeds to germinate after just 4 weeks of stratification; after this period only ca. $10 \%$ of seeds could germinate in water.

Non-stratified seeds responded to ethephon at $10^{-4} \mathrm{M}$, the highest concentration used; ca $25 \%$ of seeds germinated (Fig. 1a). This regulator, in all applied concentrations, markedly increased seed germination after various periods of stratification, the effect being dependent on its concentration and duration of stratification. The response to ethephon was more evident after 4 weeks of stratification. The stimulatory effect of ethephon at $3 \times 10^{-6}$ and $10^{-5}$
$M$ increased with the length of stratification and reached a maximum after 20 weeks; resulting in $80-90 \%$ germination. The highest germination improvement was observed after ethephon application at $10^{-4} \mathrm{M}$; ca. $80 \%$ of seeds germinated just after 8 weeks when in the control only about $10 \%$ of seeds germinated. ABA, known to be responsible for seed dormancy maintenance, at $3 \times 10^{-6}$ and $10^{-5} \mathrm{M}$ slightly inhibited germination of partially stratified seeds; the effect decreased with increasing time of stratification (Fig. 1a). At $3 \times 10^{-5} \mathrm{M}$, the highest concentration, ABA inhibited germination of stratified seeds for longer than 4 weeks. After 16-20 weeks of stratification only ca $10 \%$ of seeds were able to germinate in the presence of $\mathrm{ABA}$ at the above concentration.

A beneficial effect of a prolonged period of stratification on seed germination was also evident when germination rate was considered (Fig. 2a). Stratification for the period between 4 and 20 weeks increase the rate of seed germination over 3 times. Only at its highest concentration did $\mathrm{GA}_{3}$ increase the rate of germination of seeds stratified for various periods. Ethephon also increased the rate of germination of seeds stratified for various periods (Fig. 2a). After 4 weeks of stratification this compound was effective only at the highest concentration, but with an increasing duration of stratification a stimulatory effect was evident at lower concentrations of ethephon. At $10^{-5}$ and $3 \times 10^{-5} \mathrm{M}$, ABA lowered the rate of germination but the effect was significant only in seeds stratified for 20 weeks (Fig. 2a).

\section{Germination at $35^{\circ} \mathrm{C}$}

Dormant seeds did not able to germinate at $35{ }^{\circ} \mathrm{C}$ (Fig. 1b). Stratification for only 4 weeks caused ca. $65 \%$ of seeds to germinate. Extension of the stratification period did not markedly increase germination; germination reached $75 \%$. At $10^{-3} \mathrm{M}, \mathrm{GA}_{3}$ caused ca. $25 \%$ germination of nonstratified seeds. At concentrations below $10^{-3} \mathrm{M}$, this regulator did not affect germination of seeds stratified for various periods. However, $\mathrm{GA}_{3}$ at $10^{-3} \mathrm{M}$ allowed for $80-90 \%$ seed germination independently of a period of stratification. Ethephon at $10^{-4} \mathrm{M}$ increased germination of non-stratified seeds up to almost $40 \%$ (Fig. 1b). This compound, applied even at the lowest concentration, i.e. $3 \times 10^{-6} \mathrm{M}$, caused that almost all seeds were able to germinate after just 4 weeks of stratification; $90 \%$ seeds germinated. At $3 \times 10^{-6} \mathrm{M}$, ABA partially inhibited the germination of stratified seeds (Fig. 1b). ABA's inhibitory effect clearly occurred at $10^{-5}$ and $3 \times 10^{-5} \mathrm{M}$ concentrations, as only $10-15 \%$ of seeds stratified for 4 weeks germinated in comparison to $65 \%$ in the control. The extent of inhibition decreased with prolonged stratification.

The rate of germination at $35{ }^{\circ} \mathrm{C}$ (Fig. 3) was higher than at $25{ }^{\circ} \mathrm{C}$ (Fig. 2) after every period of stratification. 
Fig. 1 Effect of $\mathrm{GA}_{3}$, ethephon and $\mathrm{ABA}$ on percentage germination of $A$. retroflexus seeds at 25 (a) and $35{ }^{\circ} \mathrm{C}$ (b) after various periods of stratification at $4{ }^{\circ} \mathrm{C}$. Germination was determined after 7 days of incubation. The vertical bars indicate \pm SD. Two-way ANOVA with the Duncan post hoc test was used to determine significant differences. Mean values with different letters $(a-i)$ are significantly different $(P \leq 0.05)$ $25^{\circ} \mathrm{C}$ darkness

(A) $35^{\circ} \mathrm{C}$ darkness

(B)
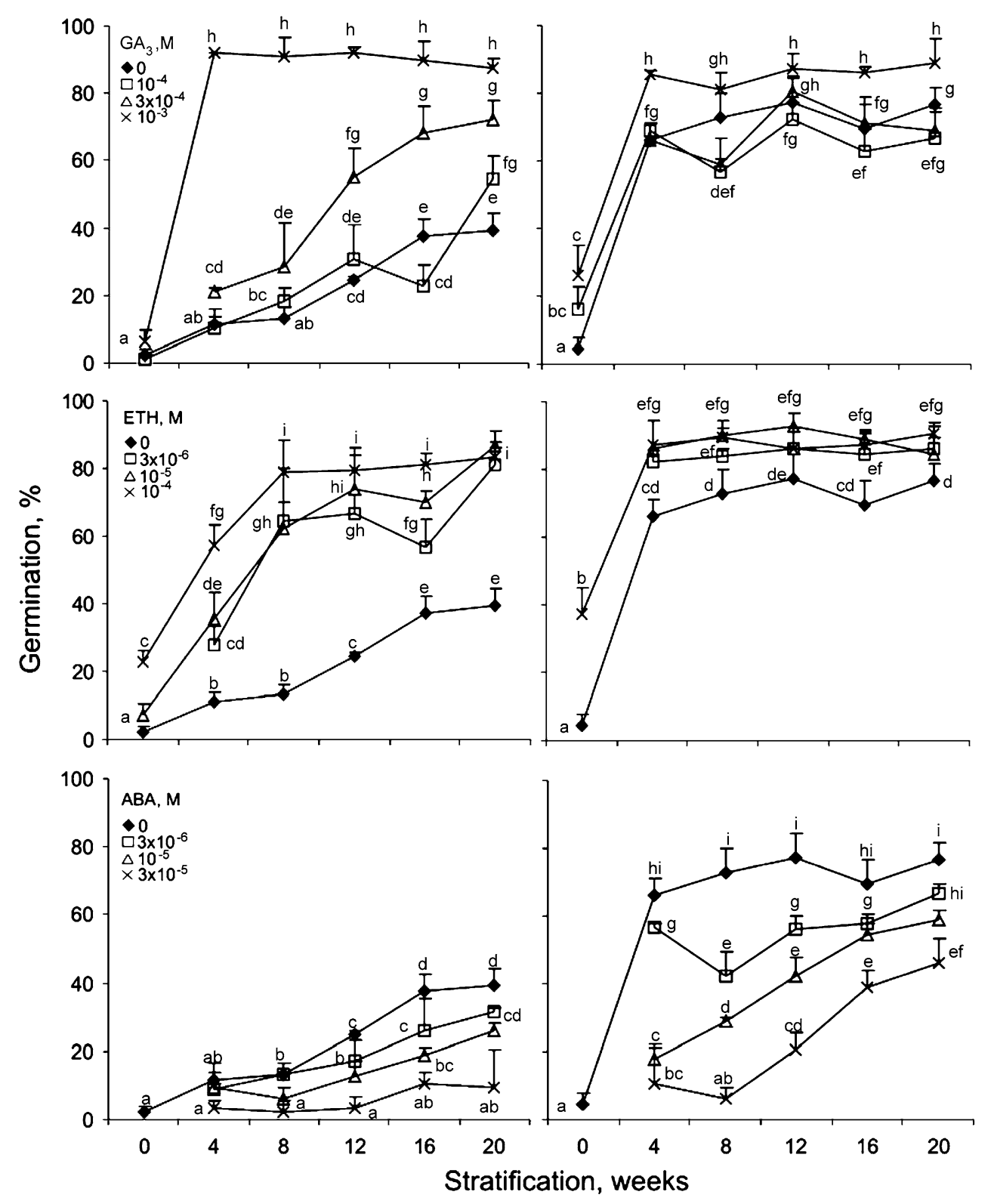

Both $\mathrm{GA}_{3}$ and ethephon did not or only slightly increased the rate of germination (Fig. 3). ABA markedly decreased the rate of germination of seeds stratified for 4-20 weeks when applied at $10^{-5}-3 \times 10^{-5} \mathrm{M}$ (Fig. 3).

Effects of $\mathrm{GA}_{3}$, ethephon and $\mathrm{ABA}$ presence during stratification on subsequent seed germination

$\mathrm{GA}_{3}$, ethephon and $\mathrm{ABA}$ were applied during stratification conducted for 4,8 and 12 weeks, and then germination at $35{ }^{\circ} \mathrm{C}$ determined. Seeds stratified for 4 and 8 weeks germinated to 50 and $60 \%$ respectively (Fig. 4a). After
12 weeks of stratification, $75 \%$ of seeds germinated. $\mathrm{GA}_{3}$ and ethephon allowed almost all seeds to germinate after stratification for 8 weeks. During the 4 week stratification period, the application of ABA resulted in markedly inhibited germination; around $20 \%$ seeds germinated in comparison to $50 \%$ in the control. The inhibitory effect of ABA disappeared after a prolongation of the stratification time. $\mathrm{GA}_{3}$ and ethephon increased, whereas ABA decreased, the rate of germination after 4 weeks of stratification (Fig. 4b). After a prolonged stratification in the presence of $\mathrm{ABA}$ the germination rate was similar to that in control. 

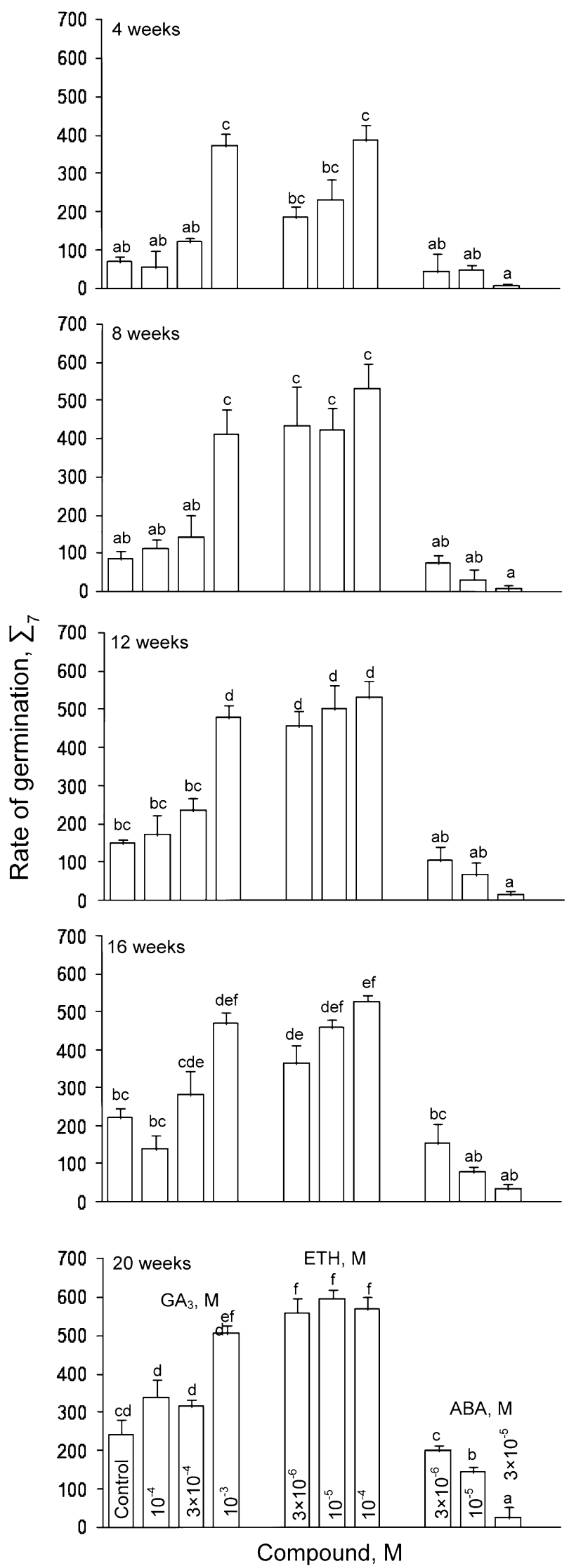

4Fig. 2 The effect of $\mathrm{GA}_{3}$, ethephon and $\mathrm{ABA}$ on the rate of $A$. retroflexus seed germination at $25{ }^{\circ} \mathrm{C}$ after various periods of stratification at $4^{\circ} \mathrm{C}$. The vertical bars indicate $\pm \mathrm{SD}$. Two-way ANOVA with the Duncan post hoc test was used to determine significant differences. Columns with different letters $(a-f)$ are significantly different $(P \leq 0.05)$

Effect of $\mathrm{GA}_{3}$, ethephon and $\mathrm{ABA}$ on germination, at 25 and $35{ }^{\circ} \mathrm{C}$, of seeds stratified under natural conditions in soil

Both $\mathrm{GA}_{3}$ and ethephon, at the highest concentrations, increased the percentage of germination at $25{ }^{\circ} \mathrm{C}$ of seeds stratified in Petri dishes placed in soil for 4 weeks, from November to December (average temperature $5 \mathrm{~cm}$ below the surface of soil ranging $4.0-3.3^{\circ} \mathrm{C}$ and minimal temperature ranging from -2.7 to $-7.6{ }^{\circ} \mathrm{C}$; Fig. 5a). $\mathrm{GA}_{3}$ stimulated germination more effectively than ethephon, whereas ABA did not affect germination. At $35^{\circ} \mathrm{C}, \mathrm{GA}_{3}$ and ethephon enabled the germination of almost all stratified seeds (Fig. 5c). ABA completely inhibited germination when applied at the highest concentration. $\mathrm{GA}_{3}$ and ethephon strongly increased the rate of germination at 25 and $35^{\circ} \mathrm{C}$ (Fig. 5b, d). Strong inhibition of seed germination rate resulting from the application of $10^{-4} \mathrm{M} \mathrm{ABA}$ occurred only at $35{ }^{\circ} \mathrm{C}$ (Fig. 5d).

Effect of $\mathrm{GA}_{3}$, ethephon and $\mathrm{ABA}$ on seed germination after various periods of outdoor burial in soil

\section{Germination at $25^{\circ} \mathrm{C}$}

Seeds were buried for various periods and their germination in the presence of the various regulators at $25{ }^{\circ} \mathrm{C}$ was determined. One and two months of burial (with average temperatures ranging from 4.4 to 5.6 and minimal temperatures ranging from -1.2 to $2.3{ }^{\circ} \mathrm{C}$; Fig. 6a) during the experiment started in November 2006, resulting in ca. $60 \%$ seed germination at $25{ }^{\circ} \mathrm{C}$ (Fig. 6c). Prolonged burial until March and May 2007 increased germination to 90 and $75 \%$, respectively. Further extension of the stratification period decreased the percentage of seed germination. The lowest level of germination, $25 \%$, was noted in the case of seeds recovered in September 2007. The germination of recovered seeds increased again in December 2007 and reached $75 \%$. Both $\mathrm{GA}_{3}$ and ethephon increased the germination of seeds exhumed from December 2006 to February 2007; 80-95 \% seeds germinated. ABA lowered germination of the seeds buried from November 2006 till April 2007, from about 60 to $90 \%$ in control to about 10-35\%. The effect of this hormone decreased with stratification time extended until May. ABA also markedly 

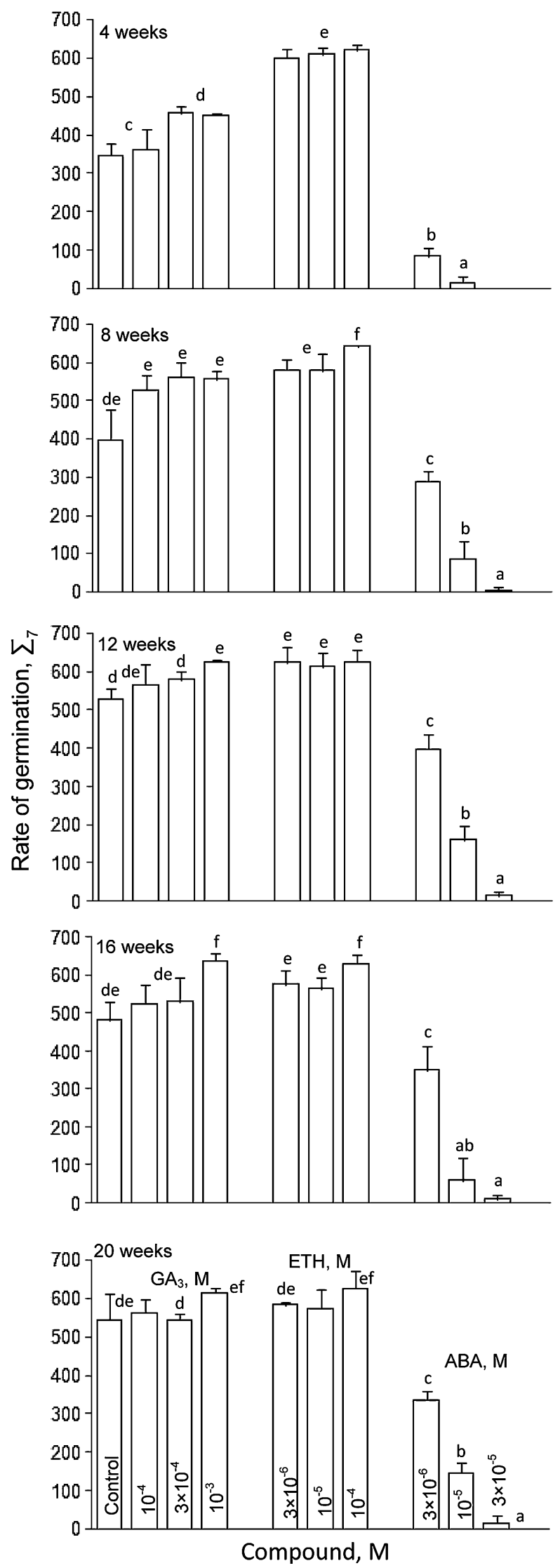

4Fig. 3 The effect of $\mathrm{GA}_{3}$, ethephon and $\mathrm{ABA}$ on the rate of $A$. retroflexus seed germination at $35{ }^{\circ} \mathrm{C}$ after various periods of stratification at $4^{\circ} \mathrm{C}$. The vertical bars indicate $\pm \mathrm{SD}$. Two-way ANOVA with the Duncan post hoc test was used to determine significant differences. Columns with different letters $(a-f)$ are significantly different $(P \leq 0.05)$

inhibited germination of seeds exhumed in December 2007. In the presence of ABA only ca. $20 \%$ seeds germinated in comparison to $75 \%$ of seeds in the control group. In the experiment started in November 2007, the highest level of germination at $25{ }^{\circ} \mathrm{C}$ was observed when seeds were buried during the period of DecemberMarch (average temperatures ranging 1.8-3.4 and minimal temperature ranging from -3.3 to $0.1{ }^{\circ} \mathrm{C}$; Fig. $6 \mathrm{~b}$ ); the percentage of seeds that germinated reached $55-60 \%$ (Fig. 6d). Then, similar to the previous experiment, their germination ability lowered during summer months and then increased again when seeds were removed from soil in December 2008. $\mathrm{GA}_{3}$ enhanced germination of seeds removed from soil in January and February; $90 \%$ of the seeds germinated. Ethephon increased germination of seeds buried up until March; 75-90 \% of the seeds germinated. After an extended period of burial, however, seeds did not show such a sensitivity to these hormones. ABA inhibited germination of seeds exhumed in December 2007, January 2008 and February 2008 (Fig. 6d).

$\mathrm{GA}_{3}$ and ethephon increased not only percentage germination at $25{ }^{\circ} \mathrm{C}$, but also its rate (Fig. 8a).In contrast to ethephon, $\mathrm{GA}_{3}$ did not affect the rate of germination of seeds removed from soil in December. Ethephon was more effective than $\mathrm{GA}_{3}$ in increasing the rate of germination of seeds buried until January. Seeds recovered in February responded similarly to ethephon and $\mathrm{GA}_{3}$ (Fig. 8a). ABA strongly inhibited the rate of germination during the whole burial period (Fig. 8a).

\section{Germination at $35^{\circ} \mathrm{C}$}

Germination at $35{ }^{\circ} \mathrm{C}$ of seeds buried from 2006 November until May 2007 ranged between 80 and $95 \%$ and then markedly decreased to 20 and $30 \%$ for seeds exhumed in June and September, respectively (Fig. 7a). Seeds removed from soil in December 2007 recovered the ability of germination and $80 \%$ of seeds germinated. The burial of seeds from November 2007 until February 2008 resulted in germination of $80-95 \%$ of seeds (Fig. 7b). Again, the seeds showed lower germination after burial until September and an increase in germination percentage was observed in December. $\mathrm{GA}_{3}$ and ethephon increased germination only in the case of seeds exhumed in September 2007 (Fig. 7a). In both experiments ABA inhibited germination of buried seeds at all periods (Fig. 7a, b). The 

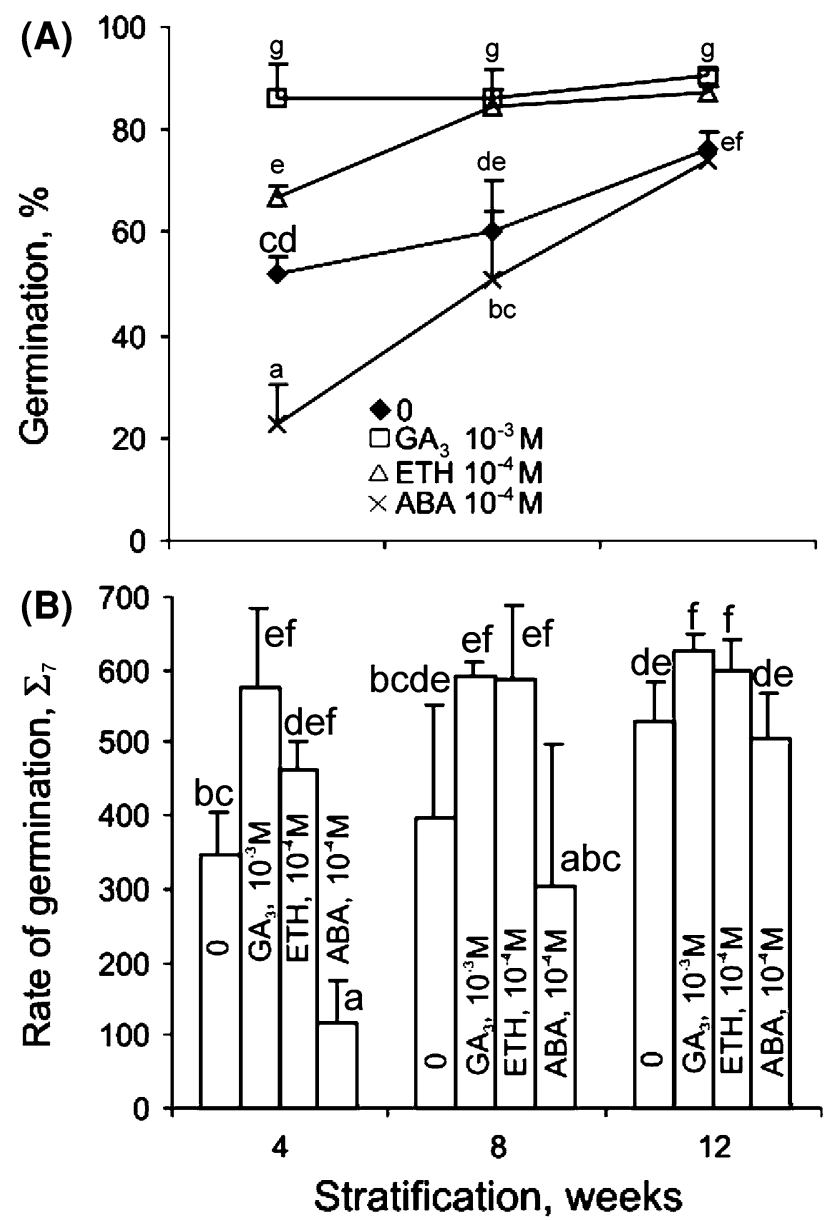

Fig. 4 The effect of stratification of A. retroflexus seeds at $4^{\circ} \mathrm{C}$ in the presence of $\mathrm{GA}_{3}$, ethephon and $\mathrm{ABA}$ on percentage (a) and rate (b) of germination at $35^{\circ} \mathrm{C}$. The vertical bars indicate \pm SD. Twoway ANOVA with the Duncan post hoc test was used to determine significant differences. Mean values with different letters $(a-g)$ are significantly different $(P \leq 0.05)$

rate of germination also showed seasonal changes, being similar from December to March, lowered until September and increased again in December (Fig. 8b). GA 3 and ethephon did not affect the rate of germination excluding seeds removed in September. ABA strongly inhibited the germination rate of seeds buried for various periods.

\section{Discussion}

Burial

It has been demonstrated previously that primarily dormant seeds of A. retroflexus cannot germinate in darkness at $25^{\circ} \mathrm{C}$ and can either germinate fully or partially at $35^{\circ} \mathrm{C}$ (Kępczyński et al. 1996; Kępczyński et al. 2003b). In the present study, the seeds of $A$. retroflexus were not able to germinate at $35{ }^{\circ} \mathrm{C}$ in darkness, indicating a high level of primary dormancy (Fig. 1). These seeds were considered fully dormant. Primarily dormant seeds of A. retroflexus, similar to previous studies (Egley 1989), showed cyclic changes in dormancy as indicated by varying germinability following their recovery from soil after varying periods of burial. Primary dormancy of A. retroflexus seeds buried in 2006/2007 (Fig. 6c) and 2007/2008 (Fig. 6d) seasons was completely or partially removed, probably mainly due to low temperatures during late autumn and winter (Fig. 6a, b). A primary role played by seasonal soil temperature changes in temporal changes of seed dormancy of summer annual A. retroflexus had been postulated previously (Omami et al.1999). Decreased germination during summer months is probably associated with an induction of secondary dormancy in these seeds caused by increasing temperatures as has also been suggested by Egley (1989). A possible induction of secondary dormancy by high temperature has been shown in an experiment with A. caudatus seeds (Kępczyński and Bihun 2002). In addition, A. quitensis and A. palmeri seeds have shown a seasonal dormancy pattern (Faccini and Vitta 2005; Jha et al. 2010), indicating that the behavior of seeds kept in soil is characteristic for the genus Amaranthus. Similarly, dormancy of other annual species has been released due to a low temperature during burial and reinduced by a high temperature (Karssen 1995). Burial at low temperatures, between November 2006 and May 2007 or between November 2007 and March 2008, enabled partial or total germination not only at $35{ }^{\circ} \mathrm{C}$ (Fig. 7), but also at a lower temperature, i.e. $25^{\circ} \mathrm{C}$ (Fig. 6). Thus, releasing dormancy in these seeds was expressed in their different ability to germinate at the above temperatures. Low temperatures, during November and December, also removed secondary dormancy, since seeds were again able to germinate at 25 and $35^{\circ} \mathrm{C}$. The occurrence of such temporal changes in dormancy of buried A. retroflexus seeds has been interpreted as an adaptation to enhance survival when seeds are in the soil, especially when they are deeply buried (Omami et al. 1999). However, it has been shown that there is no close relationship between dormancy and persistence (Thompson et al. 2003).

Ethylene, liberated from ethephon, only partially released dormancy in fully dormant seeds (Fig. 1). Burial for the first months, from November 2006 to February 2007 and from November 2007 to March 2008, increased the seed response to ethylene at $25^{\circ} \mathrm{C}$, but not at $35^{\circ} \mathrm{C}$. The seeds which passed into secondary dormancy due to burial during summer months, showed lower response to ethylene at $25{ }^{\circ} \mathrm{C}$ than primary dormant seeds. A similarly low response of secondary dormant $A$. retroflexus seeds to ethylene had been reported by Egley (1989). GA 3 , in contrast to ethylene, very slightly affected fully dormant seeds only at $35{ }^{\circ} \mathrm{C}$ (Fig. 1). Seeds buried for various 
Fig. 5 The effect of $\mathrm{GA}_{3}$, ethephon and $\mathrm{ABA}$ on percentage $(\mathbf{a}, \mathbf{c})$ and rate $(\mathbf{b}, \mathbf{d})$ of germination at $25(\mathbf{a}, \mathbf{b})$ and $35^{\circ} \mathrm{C}(\mathbf{b}, \mathbf{d})$ of $A$. retroflexus seeds after 4 weeks of stratification in soil. The vertical bars indicate \pm SD. Two-way ANOVA with the Duncan post hoc test was used to determine significant differences. Columns with different letters $(a-h)$ are significantly different $(P \leq 0.05)$

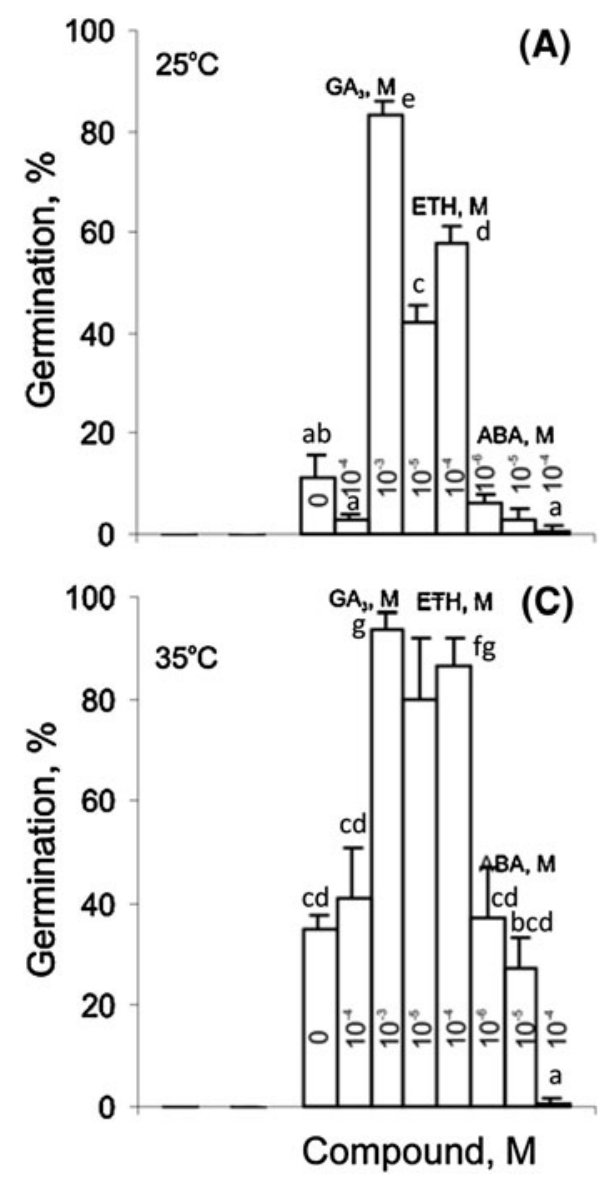

periods, showed similar responses to $\mathrm{GA}_{3}$ and to ethylene (Figs. 6, 7). However, ethylene was more effective than $\mathrm{GA}_{3} 10$ times lower concentration of ethephon than $\mathrm{GA}_{3}$ was required. The response to ABA decreased until May 2007 (Fig. 6c) and March 2008 (Fig. 6d), and increased again when secondary dormancy was partially removed due to low temperature next autumn. Increased response of A. retroflexus seeds to exogenous ethylene and gibberellin might be associated with an increasing synthesis and/or increased tissue sensitivity to these hormones during the first months of burial. Conversely, releasing dormancy due to burial associated with a decreasing response of seeds to ABA may involve a lowering content and/or decreased sensitivity to this hormone. The above hypothesis can be supported by results of experiments with seeds of Arabidopsis ecotype Cape Verdi Isle (Cvi) (Footitt et al. 2011). Dormancy cycling in seeds of this plant was related to changing synthesis of $\mathrm{ABA}$ and $\mathrm{GA}_{3}$. Dormancy increased during winter as soil temperature declined and the expression of ABA synthesis and gibberellic acid catabolism genes increased. Then dormancy declined in spring and summer, while endogenous ABA decreased and GA synthesis genes increased. It was also suggested that $\mathrm{ABA}$ signaling and sensitivity are more likely regulators of dormancy in these seeds than the absolute level of ABA.
Stratification

Stratification, an effective way of alleviating seed dormancy in summer annuals (Bewley and Black 1994), released A. retroflexus seed dormancy gradually over time (Fig. 1). Seeds stratified at $4{ }^{\circ} \mathrm{C}$ for 4 and 20 weeks were only partially able to germinate at $25{ }^{\circ} \mathrm{C}$ but germinated almost completely at $35{ }^{\circ} \mathrm{C}$. Thus, stratification at a constant temperature (Figs. 1, 2, 3, 4) was less effective in releasing dormancy than autumn-winter burial of seeds (Figs. 6, 7, 8). Since stratification at naturally occurring fluctuating soil temperatures (Fig. 5) had a similar effect to stratification at a constant temperature in an incubator, other factors might probably be responsible for the difference between the effects of burial and stratification. In the soil, seeds are exposed not only to fluctuating temperatures, but also to several other factors such as compounds solutions, gases and soil microorganisms, which may affect the dormancy state of seeds. Microorganisms are considered the primary source of biologically active substances in soil (Rodríguez-Gacio et al. 2009). Plant growth promoting rhizobacteria, that colonize roots, have been applied to a wide range of agricultural species for the purpose of the growth enhancement, including increased emergence (Kloepper et al. 1980, 1991). Naturally occurring soil 
Fig. 6 Seasonal changes in temperature $(\mathbf{a}, \mathbf{b})$ and response to $\mathrm{GA}_{3}$, ethephon and $\mathrm{ABA}$ at $25{ }^{\circ} \mathrm{C}$ of $A$. retroflexus seeds buried in 2006-2007 (c) and 2007-2008 (d). Average monthly and minimum temperatures at depth of $5 \mathrm{~cm}$ based on readings taken by

Szczecin Department of

Meteorology and Water

Management. The vertical bars indicate \pm SD. Two-way ANOVA with the Duncan post hoc test was used to determine significant differences. Mean values with different letters $(a-j)$ are significantly different $(P \leq 0.05)$

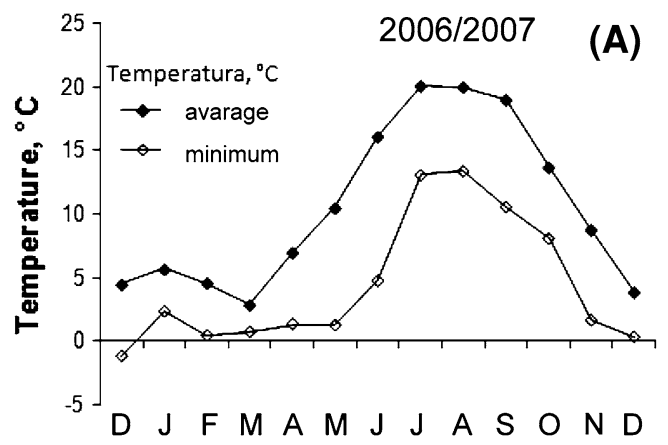

Time, month

$2006 / 2007$

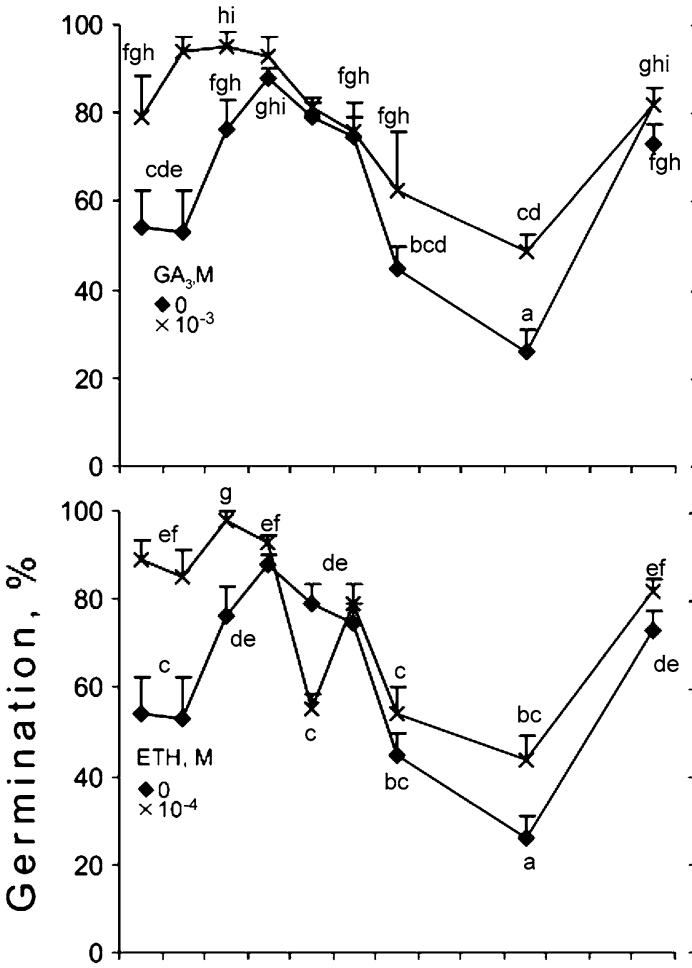

(C)

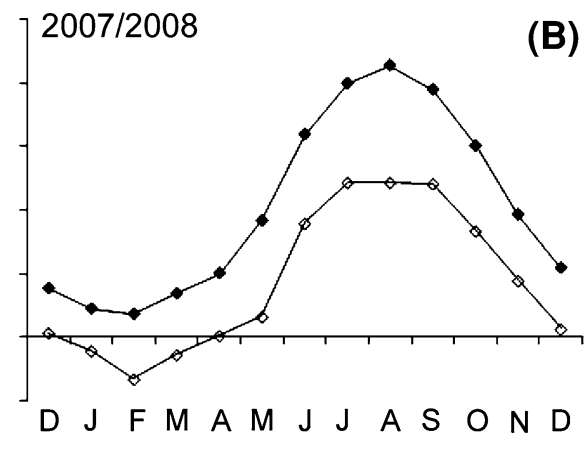

Time, month

$2007 / 2008$

(D)
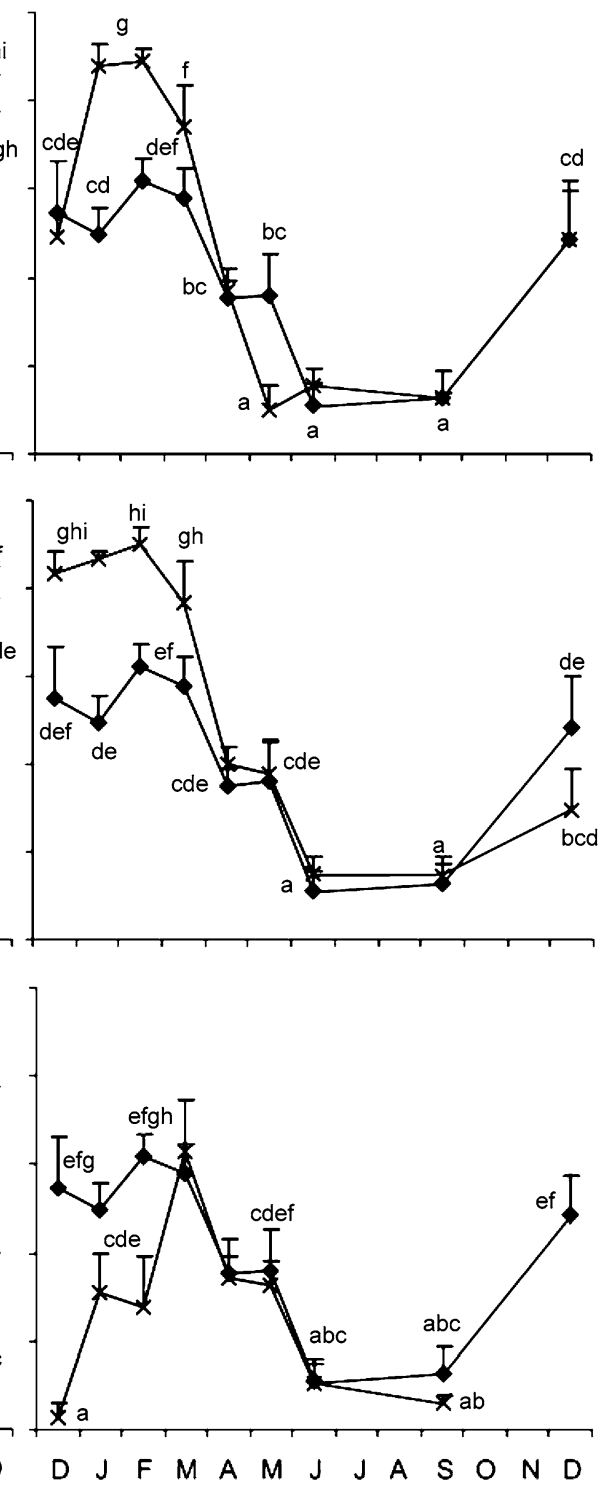

Time, month 
Fig. 7 The effect of $\mathrm{GA}_{3}$, ethephon and ABA on percentage germination of A. retroflexus seeds at $35^{\circ} \mathrm{C}$ after various periods of burial in 2006/2007 (a) and 2007/2008 (b). The vertical bars indicate \pm SD. Two-way ANOVA with the Duncan post hoc test was used to determine significant differences. Mean values with different letters $(a-i)$ are significantly different $(P \leq 0.05)$

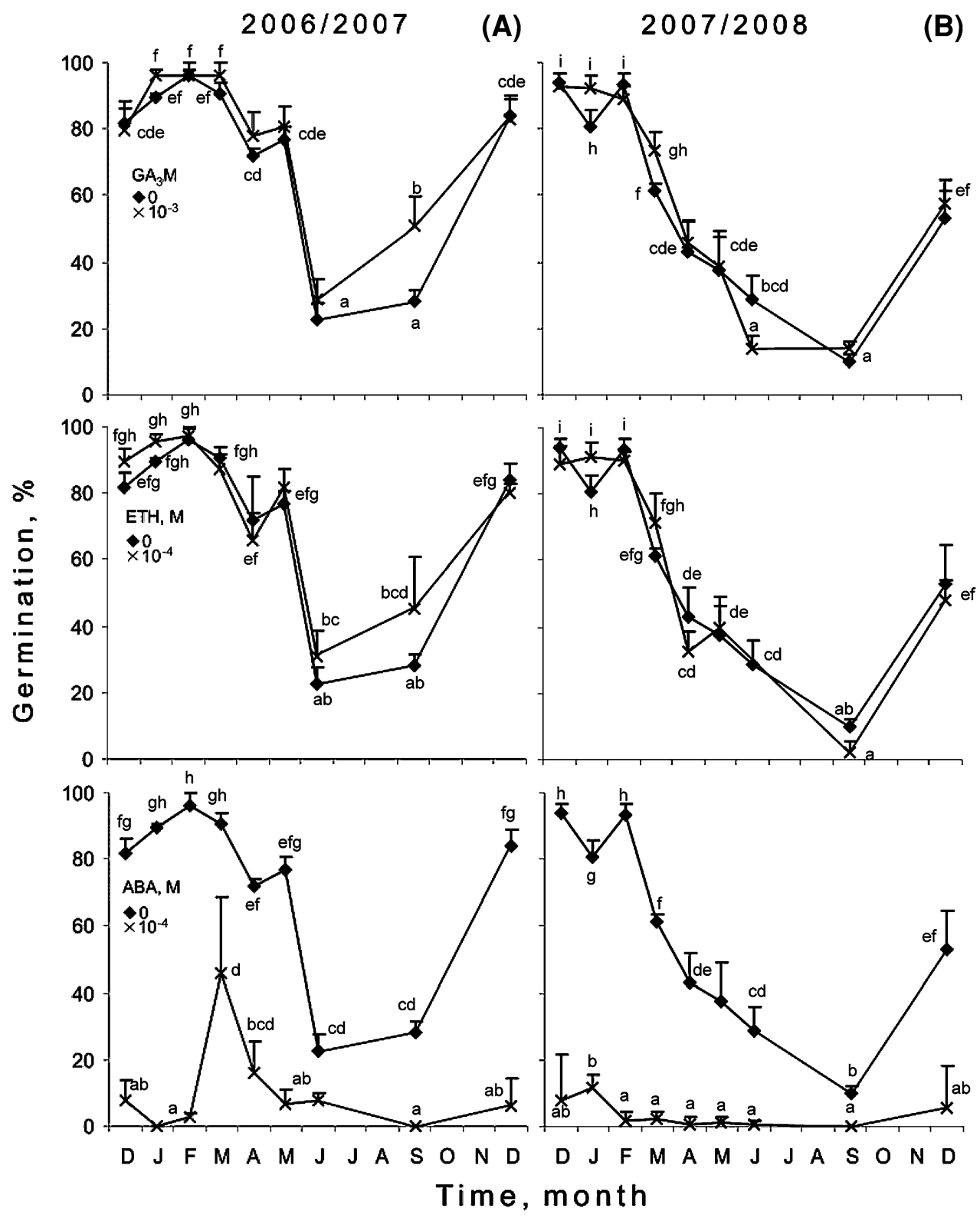

microorganisms such as Azospirillum, Azotobacter and Pseudomonas may increase Zea mays seed emergence and plant growth (Gholami et al. 2009). However, there is no evidence that the soil seed banks may be affected by hormones (Rodríguez-Gacio et al. 2009).

The stimulatory effect of $\mathrm{GA}_{3}$ and ethylene on germination of partially dormant seeds was much more evident at germination temperature $25^{\circ} \mathrm{C}$ (Figs. 1a, 2) than at $35^{\circ} \mathrm{C}$ (Figs. 1b, 3). Similar to the case of burial, ethylene was more active in stimulating germination of partially dormant seeds than $\mathrm{GA}_{3}$. Both hormones, applied after or during stratification, are able partially to replace the requirement for cold stratification of partly dormant seeds (Figs. 1, 4). The response of stratified seeds to $\mathrm{GA}_{3}$ at $25{ }^{\circ} \mathrm{C}$, gradually increased as the time of stratification of $A$. retroflexus seeds was progressing (Fig. 1). In experiments with other species it was also shown that the sensitivity to $\mathrm{GA}_{3}$ increases with the progress of dormancy release (Cadman et al. 2006; Kucera et al. 2005; Finch-Savage and Leubner-Metzger 2006). Results received in experiments with Arabidopsis thaliana showed that stratification may remove dormancy of GAdeficient mutants by increasing sensitivity to gibberellins (Karssen et al. 1989). Releasing dormancy can also be associated with an increasing gibberellin biosynthesis during stratification as has been shown in an experiment with Arabidopsis seeds (Yamauchi et al. 2004). It has also been found that the GA 20oxl gene involved in GAs biosynthesis is induced by stratification and $\mathrm{GA}_{3}$, which releases dormancy in Fagus silvatica (Calvo et al. 2004). Similar, to the case of $\mathrm{GA}_{3}$, the response to ethylene at $25{ }^{\circ} \mathrm{C}$ was also gradually 


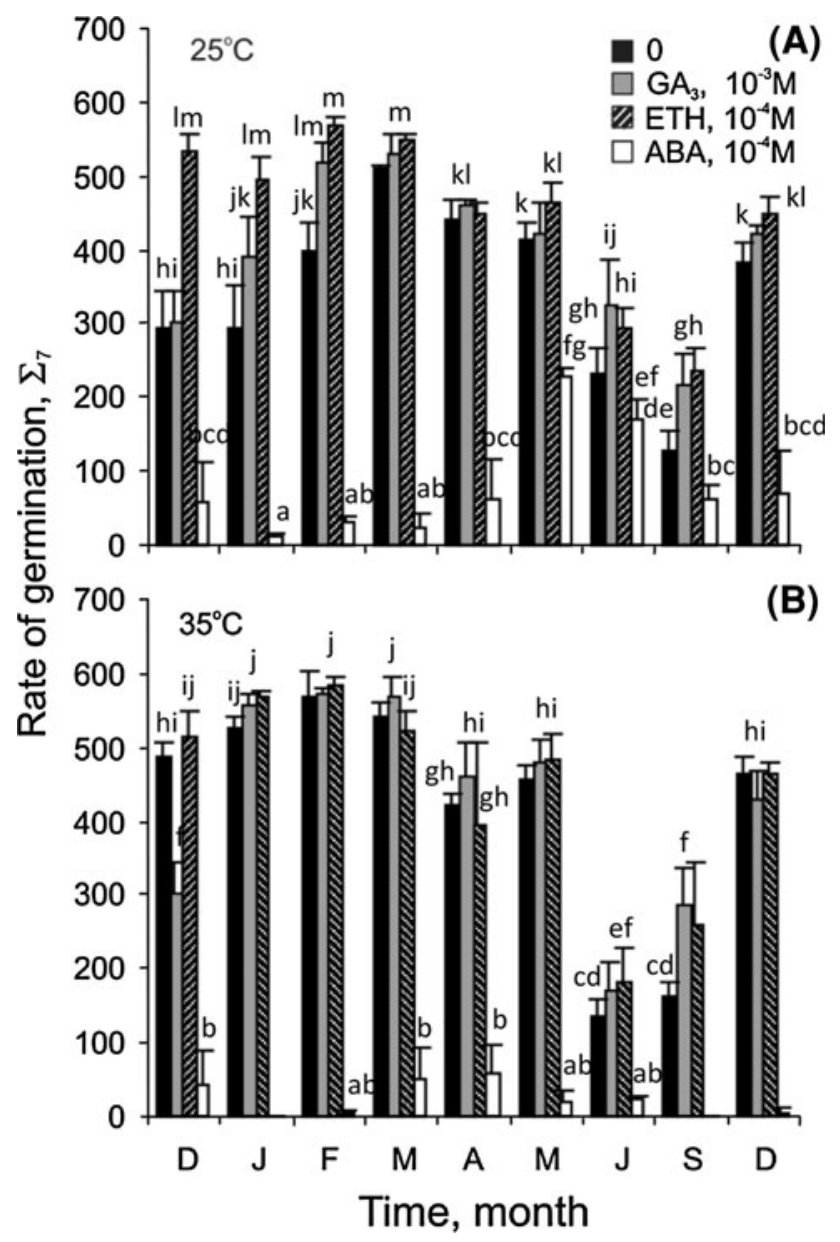

Fig. 8 The effect of $\mathrm{GA}_{3}$, ethephon and $\mathrm{ABA}$ on the rate of germination at $25{ }^{\circ} \mathrm{C}$ (a) and $35^{\circ} \mathrm{C}(\mathbf{b})$ of A. retroflexus seeds buried for various periods in 2006/2007. The vertical bars indicate \pm SD. Two-way ANOVA with the Duncan post hoc test was used to determine significant differences. Columns with different letters $(a-m)$ are significantly different $(P \leq 0.05)$

increased as the time of stratification of A. retroflexus seeds increased (Fig. 1). A transition from dormancy to germination caused by stratification of $A$. retroflexus seeds might be connected with an increasing ethylene biosynthesis. Excised apple embryos have been observed to produce progressively greater amounts of ethylene with increasing periods of stratification (Kępczyński et al. 1977). Previously it was found that dormant A. retroflexus seeds contained less, immediate precursor of ethylene biosynthesis, ACC, than non-dormant seeds (Kępczyński et al. 2003b). A cross-talk between ethylene and gibberellins in control of dormancy releasing was found. It was suggested that ethylene biosynthesis and action were involved in releasing $A$. retroflexus seed dormancy by $\mathrm{GA}_{3}$ (Kępczyński et al. 2003b). Ethephon, effective in releasing Fagus silvatica seeds dormancy stimulated the expression of GA 20oxl gene (Calvo et al. 2004). The ACC oxidase gene expression, ACC content and ethylene production were increased due to treatment of these seeds with
$\mathrm{GA}_{3}$ (Calvo et al. 2004). In contrast to $\mathrm{GA}_{3}$ and ethylene, the response of $A$. retroflexus seeds to ABA, applied after or during stratification, was decreasing as the time of stratification was progressing(Figs. 1, 4). Transition from seed dormancy state of $F$. sylvatica (Le Page-Degivry et al. 1997), A. thaliana (Ali-Rachedi et al. 2004), and Chamaecyparis nootkatensis (Schmitz et al. 2000) to germination can be associated, with decreasing ABA biosynthesis due to stratification. The loss of dormancy of A. thaliana seeds is related to the increased sensitivity to GA, decreased sensitivity to ABA and ABA/GA balance (Cadman et al 2006). Moreover, a crosstalk between ABA and GA with other signals including ethylene must be taken into account (Rodríguez-Gacio et al. 2009). Releasing dormancy in A. retroflexus seeds by stratification and ethylene might involve interaction between endogenous ABA and ethylene. Exogenous ABA has been found to decrease the effect of ethylene on germination of non-dormant Amaranthus caudatus seeds (Kępczyński et al. 2003a).

Stratification partially or almost completely released dormancy in primary dormant $A$. retroflexus seeds. Furthermore, dormancy in these seeds can be removed during burial in late autumn and winter, probably mainly due to a low temperature. Autumn-winter burial during the above seasons was found to be more effective than stratification in removing dormancy. Seeds buried during summer, due to higher temperatures, passed into secondary dormancy which was released probably by low temperatures in October and November. Both the burial until February 2007 or March 2008 and stratification increased response to $\mathrm{GA}_{3}$ and ethylene. Response to ABA was decreasing as the stratification time was progressing and as the times of burials were progressing until May 2007 or March 2008 in the two conducted experiments. Endogenous $\mathrm{GA}_{\mathrm{n}}$, ethylene and ABA might probably be involved in the control of dormancy state and germination of A. retroflexus. Releasing dormancy by stratification or partial burial could be associated with a changing in $\mathrm{ABA} / \mathrm{GA}$ and ehylene balance and/or sensitivity to these hormones.

Open Access This article is distributed under the terms of the Creative Commons Attribution License which permits any use, distribution, and reproduction in any medium, provided the original author(s) and the source are credited.

\section{References}

Ali-Rachedi S, Bouinot D, Wagner MH, Bonnet M, Sotta B, Grappin P, Jullien M (2004) Changes in endogenous abscisic acid levels during dormancy release and maintenance of mature seeds: studies with the Cape Verde Islands ecotype, the dormant model of A. thaliana. Planta 219:479-488

Bewley JD, Black M (1994) Seeds: physiology of development and germination. Plenum, Berlin 
Cadman CSC, Toorop PE, Hilhorst HWM, Finch-Savage WE (2006) Gene expression profiles of Arabidopsis cvi seeds during dormancy cycling indicate a common underlying dormancy control mechanism. Plant J 46:805-822

Calvo AP, Nicolás C, Nicolás G, Rodriguez D (2004) Evidence of a cross-talk regulation a GA 20-oxidase (FsGA20oxl) by gibberellins and ethylene during the breaking of dormancy in Fagus sylvatica seeds. Physiol Plantarum 120:623-630

Costea M, Weaver SE, Tardif FJ (2004) The biology of Canadian weeds. 130. A. retroflexus L., A. powellii S. Watson and A. hybridus L. Can J Plant Sci 84:631-668

Egley GH (1989) Some effects of nitrate-treated soil upon the sensitivity of buried redroot pigweed (A. retroflexus L.) seeds to ethylene, temperature, light and carbon dioxide. Plant, Cell Environ 12:581-588

Faccini D, Vitta JI (2005) Germination characteristics of A. quitensis as affected by seed production date and duration of burial. Weed Res 45:371-378

Finch-Savage WE, Leubner-Metzger G (2006) Seed dormancy and the control of germination. New Phytol 171:501-523

Finkelstein R, Reeves W, Ariizumi T, Steber C (2008) Molecular aspects of seed dormancy. Annual Rev Plant Biol 59:387-415

Footitt S, Douterelo-Soler I, Clay H, Finch-Savage WE (2011) Dormancy cycling in Arabidopsis seeds is controlled by seasonally distinct hormone-signaling pathways. PNAS 108:20236-20241

Gholami A, Shahsavani S, Nezarat S (2009) The effect of plant growth promoting rhizobacteria (PGPR) on germination, seedling growth and yield of maize. World Acad Sci Technol 49:19-24

Hilhorst HWM (2007) Definition and hypotheses of seed dormancy. In: Seed development, dormancy and germination. Ed. Bradford K, Nonogaki H. An Plant Rev 27:50-67

Holm L, Doll J, Holm E, Pancho J, Herberger J (1997) Worlds weeds: natural histories and distribution. Wiley, Toronto, pp 51-59

Jha P, Norsworthy JK, Riley MB, Bridges W Jr (2010) Annual changes in temperature and light requirements for germination of palmer amaranth (A. palmeri) seeds retrieved from soil. Weed Sci 58:426-432

Karssen CM (1995) Hormonal regulation of seed development, dormancy, and germination studied by genetic control. Seed development and germination, New York

Karssen CM, Zagorski S, Kępczyński J, Groot SPC (1989) Key role for endogenous gibberellins in the control of seed germination. Ann Bot 63:71-80

Kępczyński J, Bihun M (2002) Induction of secondary dormancy in A. caudatus seeds. Plant Growth Regul 38:135-140

Kępczyński J, Kępczyńska E (1997) Ethylene in seed dormancy and germination. Physiol Plant 101:720-726

Kępczyński J, Rudnicki RM, Khan AA (1977) Ethylene requirement for germination of partly after-ripened apple embryo. Physiol Plant 40:292-295
Kępczyński J, Corbineau F, Côme D (1996) Responsiveness of A. retroflexus seeds to ethephon, 1-aminocyclopropane 1-carboxylic acid and gibberellic acid in relation to temperature and dormancy. Plant Growth Regul 20:259-265

Kępczyński J, Bihun M, Kępczyńska E (2003a) The release of secondary dormancy by ethylene In A. caudatus L. seeds. Seed Sci Res 13:69-74

Kępczyński J, Kępczyńska E, Bihun M (2003b) The involment of ethylene in the release of primary dormancy in A. retroflexus seeds. Plant Growth Regul 38:57-62

Kloepper JW, Leong J, Teintze M, Schroth MN (1980) Enhanced plant growth by siderophores produced by plant growthpromoting rhizobacteria. Nature 286:885-886

Kloepper JW, Zablotowicz RM, Tipping EM, Lifshitz R (1991) Plant growth promotion mediated by bacterial rhizosphere colonizers. In: Keister DL, Cregan PB (eds) The rhizosphere and plant growth. Kluwer Academic, The Netherlands, pp 315-326

Kucera B, Cohn MA, Leubner-Metzger G (2005) Plant hormone interactions during seed dormancy release and germination. Seed Sci Res 15:281-307

Le Page-Degivry MT, Garello G, Barthe P (1997) Changes in abscisic acid biosynthesis and catabolism during dormancy breaking in Fagus sylvatica embryo. J Plant Growth Reg 16:57-61

Matilla AJ (2000) Ethylene in seed formation and germination. Seed Sci Res 10:111-126

Omami EN, Haigh AM, Medd RW, Nicol HI (1999) Changes in germinability, dormancy and viability of $A$. retroflexus as affected by depth and duration of burial. Weed Res 39:345-354

Rodríguez-Gacio MC, Matilla-Vázquez MA, Matilla AJ (2009) Seed dormancy and ABA signaling: the breakthrough goes on. Plant Signaling \& Behavior 4:1035-1049

Schmitz N, Abrams SR, Kermode AR (2000) Changes in abscisic acid content and embryo sensitivity to (+)-abscisic acid during the termination of dormancy of yellow cedar seeds. J Exp Bot 51:1159-1162

Schonbeck MW, Egley GH (1981) Changes in sensitivity of A. retroflexus $\mathrm{L}$ seeds to ethylene during preincubation. II. Effects of alternating temperature and burial in soil. Plant, Cell Environ 4:237-242

Thompson K, Ceriania RM, Bakkera JP, Bekkera RM (2003) Are seed dormancy and persistence in soil related? Seed Sci Res 13:97-100

Timson I (1965) New methods of recording germination data. Nature 207:216-217

Yamauchi Y, Ogawa M, Kuwahara A, Hanada A, Kamiya Y, Yamaguchi S (2004) Activation of gibberellin biosynthesis and response pathways by low temperature during imbibition of $A$. thaliana seeds. Plant Cell 16:367-378 